\title{
Influence of climate and geography on the occurrence of Legionella and amoebae in composting facilities
}

\author{
Lisa Conza ${ }^{1 *}$, Simona Casati Pagani ${ }^{1}$ and Valeria Gaia ${ }^{1,2}$
}

\begin{abstract}
Background: The incidence of Legionnaires' disease (LD) in southern Switzerland is three times higher than in northern Switzerland. Climatic and geographic factors may be potential causes for this difference.

We studied the prevalence of Legionella and free-living amoebae (FLA) in compost and bioaerosol in two Swiss regions to understand the role of climate and geography in the transmission of LD. We also tried to investigate whether or not compost storage duration would influence the composition of Legionella and FLA communities.

Results: A larger proportion of compost heaps in facilities from southern Switzerland harbor more diverse Legionella compared to the north $(P=0.0146)$. FLA were isolated from composts in northern facilities at slightly higher rates (88.2\% vs. 69.2\%) and at lower rates from bioaerosols (6.3\% vs. $13 \%)$ than in southern Switzerland. The diversity of FLA was higher in northern than in southern Switzerland (80\% vs. 65\%). A general decrease in the presence and variety of species was observed with decreasing compost storage time length. A discriminant model showed that values of vapour pressure, relative humidity and temperature distinguish the two regions, which were also characterised by different contamination rates by FLA and Legionella.
\end{abstract}

Conclusions: The duration of outdoor storage may favour contamination of the compost by Legionella, and may increase the number and isolation of Legionella naturally occurring in compost. The climate in the south seems to favour higher Legionella contamination of compost heaps: this could explain the higher incidence of LD in southern Switzerland.

Keywords: Legionella, Legionnaires' Disease, Free-living amoebae, Bioaerosol, Compost, Climate, Meteorological factors

\section{Background}

Legionnaires' disease (LD) is caused by inhalation of bioaerosols arising mainly from water sources containing species of Legionella [1,2], which often survive and grow within free-living amoebae [FLA; e.g. Acanthamoeba spp., Vermamoeba spp. (synonym of Hartmannella) and Naegleria spp. [3]] in water, soils and composts [4]. FLA are thought to play an important role in the survival of Legionella in compost heaps and as dispersal vehicles in bioaerosols $[5,6]$.

In-house water systems and cooling towers are considered the main, but not the only source of communityacquired LD [1,7]. In Europe, infection sources are still

\footnotetext{
*Correspondence: lisaconza@gmail.com

'Swiss National Reference Centre for Legionella, Bellinzona, Switzerland

Full list of author information is available at the end of the article
}

unknown for $52.4 \%$ of the outbreaks [2]. Soils, potting soils and composts have been associated with LD cases caused by L. longbeachae and by L. pneumophila [8-10]. Potting soils and composts have also been described as reservoirs of Legionella also in Switzerland [11,12].

In 2006-2010, the incidence of LD in Europe was about 1 case per 100,000 inhabitants per year with a mortality rate of $6.6 \%[2,13]$. In Switzerland, in the same period, the incidence was similar, being approximately 1-3 cases per 100,000 inhabitants per year with a mortality rate of $6.5 \%$ [14]; most of the cases were community acquired, sporadic and not equally distributed over the whole territory. The incidence in many Swiss Cantons corresponds to the Swiss average [14]; by contrast, in the Canton Ticino, southern Switzerland, the incidence is about 10 cases per
( Biomed Central (c) 2014 Conza et al.; licensee BioMed Central Ltd. This is an Open Access article distributed under the terms of the Creative Commons Attribution License (http://creativecommons.org/licenses/by/2.0), which permits unrestricted use, distribution, and reproduction in any medium, provided the original work is properly credited. The Creative Commons Public Domain Dedication waiver (http://creativecommons.org/publicdomain/zero/1.0/) applies to the data made available in this article, unless otherwise stated. 
100,000 inhabitants per year [14]. This high incidence could be caused to some extent by a more accurate reporting system or by a higher proportion of patients with pneumonia tested for Legionella, but other as yet unknown factors may be involved.

Climate could play an important role in the transmission of LD from sources located within the community. Switzerland is divided by the Alps that act as a barrier and create two distinct climatic zones [15]. The North of the Alps has a prevalently humid, continental climate, characterised by cold winters with little precipitations and warm summers with frequent precipitations. The South, on the other hand, is characterised by mild, wet winters, warm to hot and dry summers, and heavy rain in autumn/winter $[16,17]$, as well as by a particular geomorphology ("Insubric climate") [18]. The lowlands are located in valleys with lakes that favour dry winters with a relative humidity that at times may be as low as $20 \%$ [18]. The summer is normally dry, with heavy thunderstorms and short, heavy spells of rainfalls. Heavy and frequent rainfalls are common during the period from June to September (approx. 800-1,200 mm), with a mean annual precipitation of $1,600-2,100 \mathrm{~mm}$, in contrast to the dry summers of the Mediterranean climate [18]. The marked differences in climate between the northern and southern part of Switzerland could be a reason for the different incidence of LD in both regions. On the other hand, it cannot be excluded that differences in Legionella and FLA populations in composts and bioaerosols from the two regions may also play a role in the LD transmission. This study has thus been designed to investigate whether composting facilities in southern and northern Switzerland host different populations of Legionella and FLA. We analysed composts and bioaerosols released from facilities located in the two regions for the presence of Legionella and FLA. We collected atmospheric data and measured the temperature of the composts in all facilities studied. We also carried out a detailed investigation of different composting facilities in the Canton Ticino to investigate whether or not the duration of compost storage might influence the composition of Legionella and FLA communities.

\section{Methods}

\section{Sampling sites}

Sampling sites are listed in Table 1. We studied eight open field composting facilities (CF), of which four (CF1-CF4), located in the Canton Ticino, were sampled between May and August 2009, whereas the other four (CF5-CF8), in the Swiss northern alpine regions (Cantons of Zurich, Aargau and Lucerne) were investigated between May and August 2010 (Table 1). Open-field CF are characterised by a structured management of the green waste that are regularly mixed until maturation [11], during which bioaerosols are produced [19]. We also investigated five communal outdoor green waste centres in Ticino. Three short-term storage (CS1-CS3) and two long-term storage centres (CL1-CL2) were sampled between May and September 2008. Both types of centres collect green waste and store the material in piles. In short-term storage centres the green waste is stored for a maximum of three months, whereas in the long-term centres it is kept between three months to two years before redistribution. All $\mathrm{CF}$, short-term and long-term storage centres are distributed randomly over the territory and collect green waste from different areas of the region.

\section{Sample collection}

Bioaerosol samples were collected in different spots of all facilities, starting from the steaming compost piles up to a maximum distance of $5 \mathrm{~m}$ from the piles (green waste, ground material, middle stage and final compost). The air samples $\left(1 \mathrm{~m}^{3}\right)$ were collected in $10 \mathrm{ml}$ Page's saline solution (PAGE) with a portable cyclonic air sampler (Coriolis $\mu$, Bertin technologies, Montigny, France), as described previously [20]. Legionella and FLA isolation was carried out within $24 \mathrm{~h}$ after collection.

\section{Compost processing}

Compost samples (approx. $1 \mathrm{~kg}$ ) were collected from the steaming piles at a depth of about $30 \mathrm{~cm}$, stored in plastics bags and conserved at $4^{\circ} \mathrm{C}$; within 24 hours from collection, a $5 \mathrm{~g}$ compost portion was suspended in $10 \mathrm{ml}$ sterile PAGE and processed as described by Casati and co-workers [12].

\section{Identification of free-living amoebae}

FLA were isolated from composts and bioaerosols as described by Conza et al. [21]. Non-nutrient agar plates were inoculated with $40 \mu \mathrm{l}$ of the homogenised supernatant of the composts [11] or $50 \mu \mathrm{l}$ of the concentrated bioaerosols and incubated at $28^{\circ} \mathrm{C}$. When FLA growth was observed, the trophozoites were gently scraped from the surface of the plates and suspended in $3 \mathrm{ml}$ PAGE. Genomic DNA from FLA was extracted using the DNeasy kit (Qiagen, Hombrechtikon, Switzerland) following the manufacturer's instructions. FLA were identified by sequencing using the primers Ami6Fdeg and Ami9R [22]. The sequences obtained were compared with those available in GenBank using BLAST.

\section{Culture of Legionella from composts}

Compost samples were analysed as described by Casati et al. [11]. Isolation of Legionella was carried out after acid treatment $(0.2 \mathrm{M} \mathrm{HCl}-\mathrm{KCl}$ acid buffer) on modified Wadowsky-Yee (MWY) (Oxoid, Pratteln, Switzerland) and glycine-vancomycin-polymyxin B-cycloheximide (GVPC) (bioMérieux, Geneva, Switzerland) selective media, to 
Table 1 Sampling locations and number of samples (CS; short-term green wastes storage centres, CL; long-term green wastes storage centres, CF; composting facilities)

\begin{tabular}{|c|c|c|c|c|c|c|}
\hline \multirow[t]{2}{*}{ Facility } & \multirow[t]{2}{*}{ Region $^{a}$} & \multirow[t]{2}{*}{ Canton } & \multirow[t]{2}{*}{ No. of heaps ${ }^{b}$} & \multirow[t]{2}{*}{ Location description } & \multicolumn{2}{|c|}{ No. of samples } \\
\hline & & & & & Bioaerosol & Compost \\
\hline CF1 & $\mathrm{S}$ & Ticino & $15-20$ & Open lowland area & 4 & 2 \\
\hline CF2 & $\mathrm{S}$ & Ticino & $4-5$ & Closed area in a wood on a hilly terrain & 3 & 1 \\
\hline CF3 & $S$ & Ticino & $4-5$ & Open lowland area & 4 & 2 \\
\hline CF4 & $\mathrm{S}$ & Ticino & $15-20$ & Closed area in a wood on a hilly terrain & 4 & 2 \\
\hline CF5 & N & Zurich & $>30$ & Open lowland area & 4 & 4 \\
\hline CF6 & N & Zurich & $4-5$ & Open lowland area & 4 & 4 \\
\hline CF7 & $\mathrm{N}$ & Aargau & $15-20$ & Closed area in a wood on a hilly terrain & 4 & 4 \\
\hline $\mathrm{CF} 8^{\mathrm{C}}$ & N & Lucerne & $>30$ & Closed area in a wood on a hilly terrain & 4 & 5 \\
\hline $\mathrm{CL} 1$ & $\mathrm{~S}$ & Ticino & $2-3$ & Open lowland area & 2 & 2 \\
\hline $\mathrm{CL} 2$ & $\mathrm{~S}$ & Ticino & $2-3$ & Open lowland area & 2 & 2 \\
\hline CS1 & $\mathrm{S}$ & Ticino & $1-2$ & Open lowland area & 1 & 1 \\
\hline CS2 & $\mathrm{S}$ & Ticino & $2-3$ & Open lowland area & 2 & 0 \\
\hline CS3 & $S$ & Ticino & $1-2$ & Open lowland area & 1 & 1 \\
\hline
\end{tabular}

${ }^{a} \mathrm{~S}$, southern alpine region; $\mathrm{N}$, northern alpine region; ${ }^{b} \mathrm{No}$. of compost heaps per facility; ${ }^{c}$ Partially indoor facility.

which propiconazole (Sigma-Aldrich, Basel, Switzerland) was added at a final concentration of $5 \times 10^{-4} \mathrm{mg} / \mathrm{ml}$ to inhibit fungal growth. The limit of detection of culture for bioaerosol samples is high $\left(10^{6}\right.$ cells in $1 \mathrm{~m}^{3}$ air) [20], therefore bioaerosols were analysed by co-culture only.

\section{Co-culture of Legionella from compost and bioaerosol samples}

All compost and bioaerosol samples were analysed by co-culture as previously described [20]. $900 \mu \mathrm{l}$ of Acanthamoeba polyphaga were added to each well of a 24-well microplate (Techno Plastic Products AG, Trasadingen, Switzerland) and incubated for $1 \mathrm{~h}$ at $36^{\circ} \mathrm{C}$ to obtain an amoebal monolayer. $100 \mu \mathrm{l}$ of $1: 10^{3}$ diluted bioaerosols and compost suspensions ( $1: 10^{5}$ dilution) were then inoculated into the wells; one well containing $900 \mu \mathrm{l}$ of $A$. polyphaga suspension was added to $100 \mu \mathrm{l}$ of sterile PAGE and used as a negative control. Aliquots of $20 \mu \mathrm{l}$ were acid treated, spread on GVPC (bioMérieux) media, and incubated at $36^{\circ} \mathrm{C}$ for 5 days.

\section{Identification of Legionella isolates}

Legionellae cannot grow on substrates lacking cysteine [23]. Therefore, samples were plated on media with (BCYE, bioMérieux) and without cysteine (Columbia Blood agar base, Oxoid): colonies not growing on media without cysteine were considered to be Legionella strains and were further identified by MALDI-TOF mass spectrometry [24] or by slide agglutination (SLIDEX ${ }^{\oplus}$ Legionella; bioMérieux). Legionella pneumophila strains were characterised by indirect immunofluorescence assay, using the monoclonal antibodies from the Dresden panel [25].

\section{Meteorological parameters}

Local parameters such as air temperature $\left[{ }^{\circ} \mathrm{C}\right]$, relative humidity [\%], dew point $[\mathrm{hPa}]$ and compost temperature $\left[{ }^{\circ} \mathrm{C}\right]$ at $30 \mathrm{~cm}$ depth in the oldest compost piles (Omniport 20, $\mathrm{E}+\mathrm{E}$ Elektronik, Engerwitzdorf, Austria) were recorded during the sampling days. The dew point, which represents the temperature below which the water vapour in a volume of humid air at a constant pressure will condense into water, is a direct measure of the amount of water vapour in the air [26].

Wind speed was measured (Anemo Windmesser, Abisenvironment SA, Lonay, Switzerland) at a height of $1.8 \mathrm{~m}$ and wind direction was determined observing the dispersion of soap bubbles with the help of a compass.

\section{Meteorological data collection for the period 2007-2010}

Meteorological data were obtained from two main weather stations in Ticino and two in the northern Cantons of Zurich and Aargau for the period between January 2007 and December 2010. The meteorological data evaluated were the monthly means of temperature of the air $\left[{ }^{\circ} \mathrm{C}\right]$, relative humidity of the air [\%], pressure $[\mathrm{hPa}]$, wind speed $[\mathrm{km} / \mathrm{h}]$ and total amount of precipitations $[\mathrm{mm}]$.

A one-way analysis of variance (ANOVA) was carried out with the means of the data of two weather stations of both regions to detect any statistically significant differences that could be due to differences in sampling years.

\section{Statistical analyses}

The Simpson biodiversity index [SDI: $1-D^{\prime}=n^{*}(n-1) / N^{*}(N-$ 1)] was computed for all compost samples investigated. A Chi-square test with Yates' correction was carried out to 
determine whether or not there were significant differences among the compost samples from Ticino and from northern Swiss regions with regards to the presence of Legionella or FLA; and to compare proportion of contamination of composts with regard to Legionellapositive and FLA-positive samples. $P$-values $<0.05$ were considered statistically significant.

To assess differences among sampling sites and samples a canonical discriminant analysis was carried out using air temperature, relative humidity, dew point and wind direction, sampling hour and period (May-September), and the presence/absence of Legionella pneumophila 1 (Lp1), FLA supporting Legionella growth (Al), and both L. pneumophila (serogroups 1-15) and L. bozemanii (Lp-Lb) as independent variables. All statistical calculations were carried out using SPSS version 17.0 (SPSS Inc., Chicago, Illinois, USA).

Co-culture enrichment used in this study does not allow a quantitative assessment of the presence of Legionella, therefore all samples were classified only as positive or negative for the presence of Legionella and FLA.

\section{Results}

\section{Geographic differences}

Legionella spp

Legionella spp. were recovered from all composting facilities (CF) in Ticino and 3 out of 4 CF in northern Switzerland. In bioaerosols, Legionella pneumophila was present only in $50 \%$ of the facilities in southern Switzerland.

Legionella were isolated from $13.3 \%$ of the bioaerosols and $100 \%$ of the compost samples in Ticino. By contrast, they were not present in any of the bioaerosols and were isolated only from $35.3 \%$ of the compost heaps in facilities located in the northern region (Figure 1). A statistically

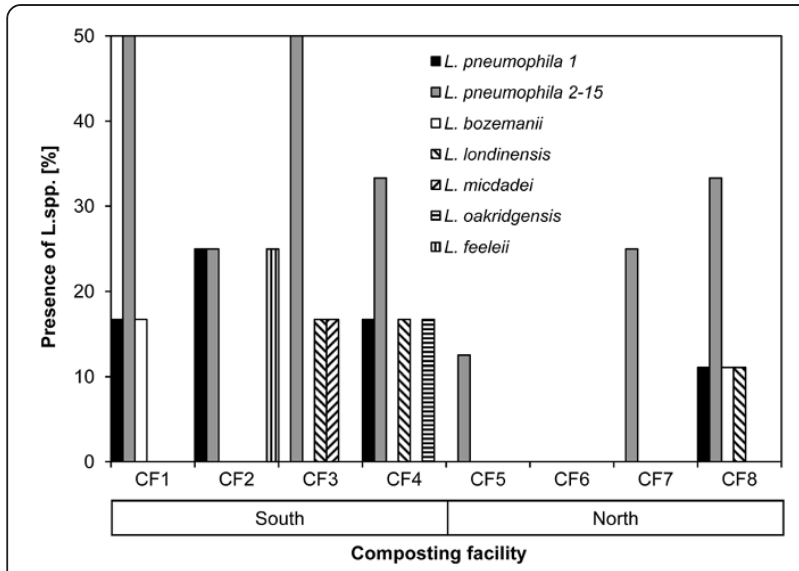

Figure 1 Cumulative presence of Legionella spp. in compost and bioaerosol samples of composting facility (CF) from Swiss southern (CF1-4) and northern (CF5-8) alpine regions. significantly higher proportion of Legionella-positive compost samples was found in CF in Ticino as compared to the north $(P=0.0146)$. For bioaerosol samples no differences were observed between the north and the south of Switzerland $(P=0.43)$.

All southern and 3 of 4 northern CF were colonised by L. pneumophila. L. pneumophila serogroup (sg) 1 was isolated in 3 of 4 facilities in Ticino but was present only in one in the northern Cantons. The Simpson biodiversity index of Legionella species was 0.75 in Ticino and 0.5 in the northern regions. Species diversity was higher in CF of Ticino, where 5 non-pneumophila species (L. bozemanii, L. cincinnatiensis, L. feeleii, L. micdadei and L. oakridgensis) were isolated as compared to two (L. londiniensis and L. bozemanii) identified in one centre in the north (Figure 1).

\section{Free-living amoebae}

FLA were isolated from $88.2 \%$ of the composts and $6.3 \%$ of the bioaerosols in the northern part of Switzerland, whereas in Ticino they were present in $64.1 \%$ of the composts and $13.9 \%$ of the bioaerosols studied. These differences, however, were not statistically significant $(P=0.89, P=1)$.

Six genera of FLA (Acanthamoeba, Vahlkampfia, Stenamoeba, Vermamoeba, Learamoeba and Singhamoeba) were recovered from the compost in the northern regions (SDI: 0.80), as compared to 5 (Acanthamoeba, Naegleria, Heterolobosea, Vahlkampfia and Stenamoeba) in Ticino (SDI: 0.65) (Figure 2 and Additional file 1). Composts from long-term storage centres and CF in Ticino contained more FLA species compared to short-term storage centres (Table 2).

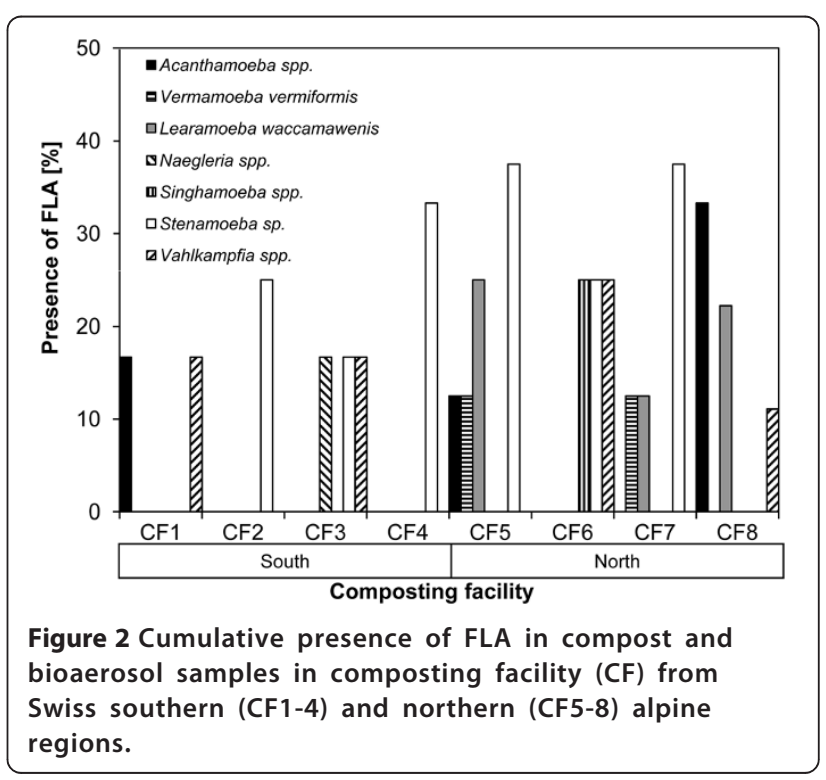


Table 2 Presence of Legionella spp. and FLA in compost and bioaerosol samples among short-term (CS), long-term (CL) storage centres and composting facilities (CF) in southern alpine region

\begin{tabular}{|c|c|c|c|c|c|c|c|c|c|}
\hline & CS1 & CS2 & CS3 & CL1 & $\mathrm{CL2}$ & CF1 & CF2 & CF3 & CF4 \\
\hline L. pneumophila 1 & - & - & - & + & + & + & + & - & + \\
\hline L. pneumophila 2-15 & + & - & + & + & + & + & + & + & + \\
\hline L. bozemanii & - & - & - & + & + & + & - & - & - \\
\hline L. londinensis & - & - & - & - & - & - & - & + & + \\
\hline L. feeleii & - & - & - & - & + & - & + & - & - \\
\hline L. oakridgensis & - & - & - & - & + & - & - & - & + \\
\hline L. cincinnatiensis & - & - & + & - & - & - & - & - & - \\
\hline L. micdadei & - & - & - & - & - & - & - & + & - \\
\hline Stenamoeba sp. & - & - & - & - & - & - & + & + & + \\
\hline Vahlkampfia spp. & - & - & - & - & - & + & - & + & - \\
\hline Acanthamoeba spp. & - & + & - & - & + & + & - & - & - \\
\hline Naegleria spp. & + & - & - & + & - & - & - & + & - \\
\hline Heterolobosea spp. & - & - & - & - & + & - & - & - & - \\
\hline
\end{tabular}

+: present; - absent.

Differences among composting facilities, short-term and long-term storage centres

CF and long-term storage centres showed the highest Legionella spp. diversity (Table 2 ). The potentially pathogenic L. pneumophila sg 1 was present in all centres but CF3. L. pneumophila sg 1 was not isolated in short-term storage centres. L. cincinnatiensis was recovered only from one short-term storage centre. In Ticino all but one storage centre was positive for L. pneumophila sg 2-15.

\section{Differences in climatic conditions among sites}

Discriminant analysis revealed that the centres investigated could be grouped according to their geographic origin. The first three canonical discriminant functions explain $85.1 \%$ of the variance of the data (Table 3). Centres CF5, CF6 and CF8 grouped together very closely, with CF7 in an isolated position, but separate from the southern alpine centres CF1-CF4 (Figure 3). The temperature of the air is responsible for a large load on the first function; relative humidity and dew point characterise the second and third functions (Table 3). The sampling days were not particularly windy and the very low wind speed could not be measured.

Meteorological characterisation of the period 2007-2010 We have also analysed the meteorological situation in the period 2007-2010. The monthly means of both regions (Additional file 2) show that climate is almost stable because no significant year-to-year differences occurred during the three sampling period. The $P$-value of one-way ANOVA of the monthly means of meteorological data from two main weather stations in Ticino and in northern

Table 3 Percentage and number of samples (in parentheses) classified among the samples taken in the different composting facilities (CF1-CF8) by canonical discriminant analysis

\begin{tabular}{|c|c|c|c|c|c|c|c|c|}
\hline \multirow{2}{*}{$\begin{array}{l}\text { Locality* } \\
\text { Observed }\end{array}$} & \multicolumn{8}{|c|}{ Predicted group membership [\%] } \\
\hline & CF1 & CF2 & CF3 & CF4 & CF5 & CF6 & CF7 & CF8 \\
\hline$\overline{C F 1}$ & $60.0(12)$ & $5.0(1)$ & $5.0(1)$ & $15.0(3)$ & $0(0)$ & $5.0(1)$ & $10.0(2)$ & $0(0)$ \\
\hline CF2 & $11.1(1)$ & $33.3(3)$ & $11.1(1)$ & $44.5(4)$ & $0(0)$ & $0(0)$ & $0(0)$ & $0(0)$ \\
\hline CF3 & $0(0)$ & $4.2(1)$ & $87.5(21)$ & $8.3(2)$ & $0(0)$ & $0(0)$ & $0(0)$ & $0(0)$ \\
\hline CF4 & $27.8(5)$ & $0(0)$ & $11.1(2)$ & $61.1(11)$ & $0(0)$ & $0(0)$ & $0(0)$ & $0(0)$ \\
\hline CF5 & $0(0)$ & $0(0)$ & $0(0)$ & $0(0)$ & $100(3)$ & $0(0)$ & $0(0)$ & $0(0)$ \\
\hline CF6 & $0(0)$ & $0(0)$ & $0(0)$ & $0(0)$ & $0(0)$ & $100(4)$ & $0(0)$ & $0(0)$ \\
\hline CF7 & $0(0)$ & $0(0)$ & $0(0)$ & $0(0)$ & $0(0)$ & $0(0)$ & $100(4)$ & $0(0)$ \\
\hline CF8 & $0(0)$ & $0(0)$ & $0(0)$ & $0(0)$ & $0(0)$ & $0(0)$ & $0(0)$ & $100(4)$ \\
\hline
\end{tabular}

$72.1 \%$ are correctly classified (predicted) by the analysis.

${ }^{*} \mathrm{CF} 1-4=$ Swiss southern composting facilities. CF5-8 = Swiss northern composting facilities. 


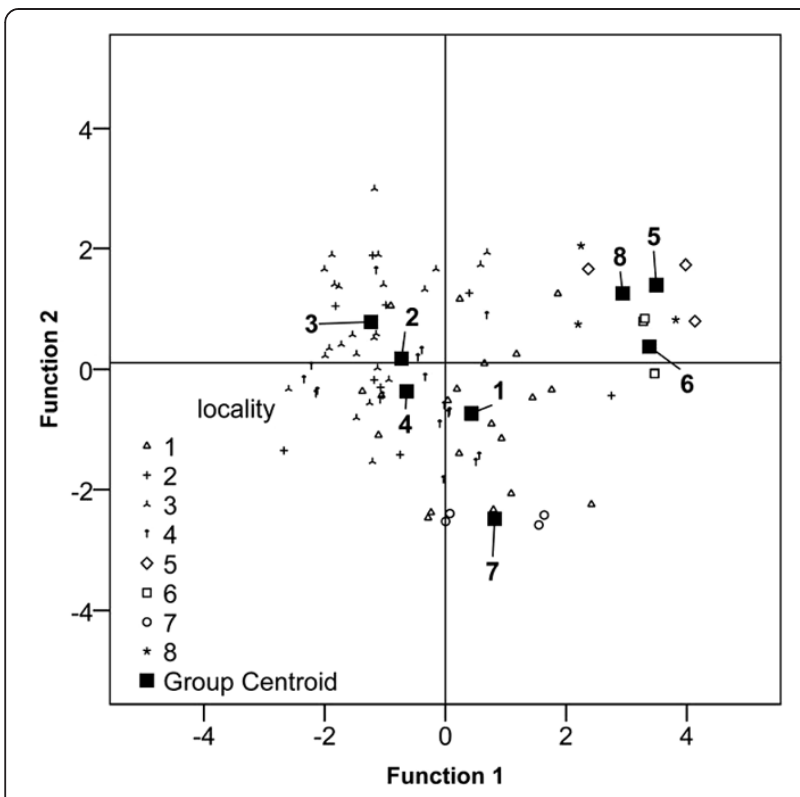

Figure 3 Graphical plot of the results of discriminant analysis. The centroids of the data originating from the southern facilities $(1-4)$ are well grouped in the central part of the graph and separated from those of the northern facilities (5-8). Total variance explained by the model: $85.1 \%$.

Switzerland are not statistically significant: temperature $(P=0.97$ in the North vs. $P=0.95$ in Ticino), relative humidity $(P=0.95$ vs. $P=0.17)$, wind speed $(P=0.90$ vs. $P=023)$, precipitation $(P=0.19$ vs. $P=0.83)$ and pressure $(P=0.11$ vs. $P=0.11)$.

\section{Discussion}

Our study shows that southern and northern compost heaps host different populations of Legionella and FLA, and the Legionella species richness is influenced by the climate and geography of the two regions. The duration of compost storage also influenced the degree of contamination of Legionella and FLA communities.

Potential human pathogenic strains of L. bozemanii, $L$. cincinnatiensis, L. feeleii, L. micdadei, L. londiniensis and L. oakridgensis were isolated mainly from samples collected in the southern part of Switzerland. The observed number of species $(S)$, however, is not a reliable index of richness because it is influenced by the evenness: the more reliable Simpson biodiversity index was $25 \%$ higher in Ticino compared to the northern region. Ticino hosts a higher diversity of Legionella compared to the north, where only L. bozemanii and L. londiniensis were recovered. L. longbeachae, reported in other studies [10], was not detected in our samples. In Switzerland, L. longbeachae has so far been reported only once from potting soils [12] and from compost [21]. L. pneumophila sg 1 was isolated from compost in $75 \%$ of the southern Swiss facilities. These results support the hypothesis of compost being a potential source of Legionella causing LD [2].

Discriminant analysis show a trend towards separation of CF according to their geographic location, with $72.1 \%$ of the cases correctly classified (Table 3); this supports the hypothesis that climate and possibly geographic factors influence compost contamination by Legionella. North-south differences, as shown by the canonical discriminant analysis, were expected if considering the climate features of the two regions [15]. The most important discriminating factors are relative humidity, temperature and dew point. Our results are consistent with previously published observations [27,28] that identified a relationship between occurrence of cases of LD and precipitation and increased humidity.

In the southern alpine region the normal relative humidity values vary between $62.8 \%$ and $68.9 \%$ from April to August, with a July monthly mean of $65.3 \%$. In the northern alpine regions the values may exceed $72 \%$ [15]. A previous study showed that L. pneumophila is more viable in the aerosols at $65 \%$ than at $72 \%$ relative humidity [29], meaning that Legionella survival is more likely in the southern alpine region. The relative humidity is indirectly proportional to temperature and for this reason the values are higher in the northern alpine region. We have observed that vapour pressure is a better discriminating factor than humidity [30]. Vapour pressure is usually higher in Ticino from April to November, being e.g. $16 \mathrm{hPa}$ in August, a month during which many LD cases are recorded [14,15], as opposed to $14.5 \mathrm{hPa}$ in the north. The climate characteristics in each region could thus play an important role in the bioaerosol stability and survival of Legionella and as a consequence in the transmission of LD.

More genera of FLA were recovered from the composts in the northern regions compared to Ticino. FLA may protect intracellular Legionella from adverse ecological factors, such as environmental conditions, nutrient starvation, biocides and predation [5]; FLA known to favour the intracellular growth of Legionella (i.e. Acanthamoeba spp., Naegleria spp., Vahlkampfia spp and Vermamoeba vermiformis) were isolated in both regions [3]. However, the presence of Legionella in compost in the south and in the north was statistically not correlated with the presence of FLA. These results must be taken with caution because of the rather small sample size and the limited number of isolated FLA.

FLA richness is apparently favoured by a combination of climatic factors [31], because more species of FLA were recovered in the northern composts, but the results may have been influenced by the low number of samples and replicates. The differences in Legionella diversity and FLA diversity, on the other hand, could be a random finding.

Long-term storage centres and CF did not show any differences in the variety of Legionella spp. and FLA spp. 
Short-term and long-term storage centres were very different with regards to contamination by Legionella spp. Duration of outdoor storage in centres, with or without structured management of green waste, is most likely influencing colonisation of the heaps by Legionella (Table 2). The differences seen between southern and northern CF and among storage centres may have different explanations. Green material in CF was described by Casati et al. [11] to be Legionella-free.

The green material composted, however, could in fact be contaminated, the concentration of Legionella cells, however, being below the limit of detection, which is $10^{2}$ CFU per $g$ of compost [20].

The differences in the climate between southern and northern regions could also influence the vegetation and thus the composition of the material collected in the compost centres. However, as the collected green waste mainly comes from gardens, this difference may have limited influence on the final compost composition.

Previously published data suggest that, once contaminated, compost heaps may become an optimal reservoir [11]. The precise mode of contamination remains controversial, but rain [11], bioaerosol and dust moved by wind may be causal factors. Even though the presence of Legionella in rainwater was not assessed in this study, viable Legionella were recently recovered in samples from pluvial floods, puddles on asphalt roads and roofharvested rainwater tanks. It would be interesting to assess if there is an increase in Legionella concentrations in samples collected near composting heaps compared to rainwater collected elsewhere [32-35].

Bioaerosols may be released from the compost passively by evaporation and heat, or actively through human activities in the facilities [19]. Compost is generally reused in agriculture, gardens and flowerbeds, or mixed with soil in potting soil. Recycling of the compost could introduce potential pathogenic Legionella into the soil or potting soil; handling of these products could generate bioaerosols or dust [36] that may be potential sources of Legionella infections $[9,37]$.

This study suffers from three limitations. One is the small number of samples and CF analysed. We used stringent criteria to choose the facilities, because we aimed at investigating open field facilities with complete and structured management of the green waste. In the southern alpine region structured green management is not common; therefore, we decided to consider also long- and short-term green waste storage centres. In the northern alpine region, open field facilities are increasingly replaced by indoor composting to exploit biogas production. We did not analyse the situation in these centres because they should not pose human health threat for community-acquired LD. This limited the availability of additional facilities for our investigations.
Further, Legionella in compost was analysed by culture and co-culture (amoebal enrichment method); in contrast, bioaerosols were analysed only by co-culture.

The results of the analysis of bioaerosols by traditional culture would have been an interesting addition to the study. In fact, co-culture performed with only one amoebal strain may have selected for particular species and may have given only a partial picture of the bacterial population within the composts.

In a pilot study, 20 bioaerosol samples were analysed by culture and co-culture in parallel (Additional file 3). Nine samples were positive only by co-culture analysis and this prompted us to analyse bioaerosol samples only by co-culture, because we assumed that the amount of Legionella cells present in the bioaerosol was too low.

Finally logistic problems hindered us to sample the different facilities during the same year and we had to carry out our sampling in different years, thus introducing a confounding factor (time) in our analysis. The one-way ANOVA carried out on the meteorological data, on the other hand, did not reveal statistically significant differences among the years with regards to the parameters investigated. Analysis of data from multiple years are thus unlikely to have influenced our observations. Sampling was also performed during the same period of the year, in summer, with constant conditions between the three years in both regions. We are thus confident that different sampling times have not influenced relevantly the outcome of the study.

\section{Conclusions}

In conclusion, $\mathrm{CF}$ of southern and northern Swiss regions host different populations of Legionella and FLA. Composts and bioaerosols in Ticino are frequently contaminated by Legionella and compost contamination by Legionella and FLA seems to increase with increasing storage time. These differences are most likely influenced by the different climates in the two regions. Future studies should address the role that CF may have in the spread of Legionella to better understand the importance of composting facilities in the transmission of LD.

\section{Additional files}

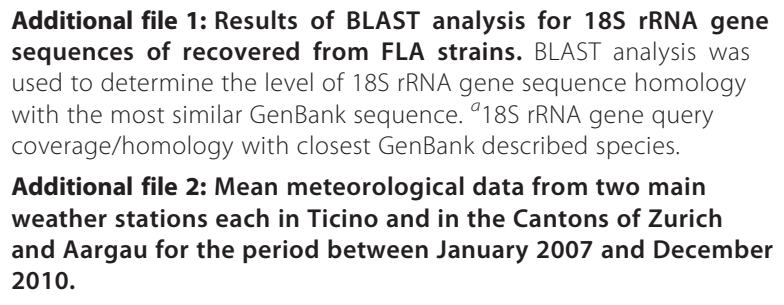

Additional file 2: Mean meteorological data from two main weather stations each in Ticino and in the Cantons of Zurich and Aargau for the period between January 2007 and December 2010. 
Additional file 3: List of all Legionella spp. recovered from bioaerosol samples analysed in parallel by culture and co-culture.

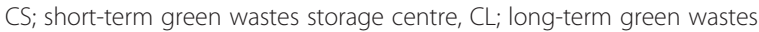
storage centre, CF; composting facility, Lp1; L. pneumophila serogroup 1 Lp2-15; L. pneumophila serogroups 2-15, -; negative sample.

\section{Competing interests}

The authors declare that they have no competing interests.

\section{Authors' contributions}

LC, SC and VG participated in the conception and design of the study and participated in the analysis and interpretation of data. LC wrote the first draft of the manuscript which was extensively reviewed by SC and VG. All authors have read and approved the final manuscript.

\section{Acknowledgements}

The work has been partially supported by the Ticino Pulmonary League and the Foundation Dr. Pierluigi Crivelli. We thank PD Dr. O. Petrini (POLE Pharma Consulting, Breganzona, Switzerland) and Prof. Th. Egli (EAWAG, Dübendorf, Switzerland) for constructive advice.

\section{Author details}

${ }^{1}$ Swiss National Reference Centre for Legionella, Bellinzona, Switzerland. ${ }^{2}$ Servizio di microbiologia EOLAB, Ente ospedaliero cantonale, Bellinzona, Switzerland.

Received: 13 October 2013 Accepted: 21 October 2014

Published: 24 November 2014

\section{References}

1. Ferre MR, Arias C, Oliva JM, Pedrol A, Garcia M, Pellicer T, Roura P, Dominguez A: A community outbreak of Legionnaires' disease associated with a cooling tower in Vic and Gurb, Catalonia (Spain) in 2005. Eur J Clin Microbiol Infect Dis 2009, 28(2):153-159.

2. Joseph CA, Ricketts KD, on behalf of the European Working Group for Legionella Infections: Legionnaires' disease in Europe 2007-2008. Euro Surveill 2010, 15(8):pii = 19493.

3. Lau HY, Ashbolt NJ: The role of biofilms and protozoa in Legionella pathogenesis: implications for drinking water. J Appl Microbiol 2009, 107(2):368-378.

4. Greub G, Raoult D: Microorganisms resistant to free-living amoebae. Clin Microbiol Rev 2004, 17(2):413-433

5. Bouyer S, Imbert C, Rodier MH, Hechard Y: Long-term survival of Legionella pneumophila associated with Acanthamoeba castellanii vesicles. Environ Microbiol 2007, 9(5):1341-1344.

6. Dey R, Bodennec J, Mameri MO, Pernin P: Free-living freshwater amoebae differ in their susceptibility to the pathogenic bacterium Legionella pneumophila. FEMS Microbiol Lett 2009, 290(1):10-17.

7. Nguyen TM, llef D, Jarraud S, Rouil L, Campese C, Che D, Haeghebaert S, Ganiayre F, Marcel F, Etienne J, Desenclos JC: A community-wide outbreak of legionnaires disease linked to industrial cooling towers-how far can contaminated aerosols spread? J Infect Dis 2006, 193(1):102-111.

8. Pravinkumar S, Edwards G, Lindsay D, Redmond S, Stirling J, House R, Kerr J, Anderson E, Breen D, Blatchford O, McDonald E, Brown A: A cluster of Legionnaires' disease caused by Legionella longbeachae linked to potting compost in Scotland, 2008-2009. Euro Surveill 2010, 15(8):19496-19496.

9. Wallis $L$, Robinson P: Soil as a source of Legionella pneumophila serogroup 1 (Lp1). Aust N Z J Public Health 2005, 29(6):518-520.

10. Steele TW, Moore CV, Sangster N: Distribution of Legionella longbeachae serogroup 1 and other legionellae in potting soils in Australia. Appl Environ Microbiol 1990, 56(10):2984-2988.

11. Casati S, Conza L, Bruin J, Gaia V: Compost facilities as a reservoir of Legionella pneumophila and other Legionella species. Clin Microbiol Infect 2009, 16(7):945-947.

12. Casati S, Gioria-Martinoni A, Gaia V: Commercial potting soils as an alternative infection source of Legionella pneumophila and other Legionella species in Switzerland. Clin Microbiol Infect 2009, 15(6):571-575.

13. ECDC: Reporting on 2009 surveillance data and 2010 epidemic intelligence data. Annual Epidemiological Report 2011. European Centre for Disease Prevention and Control (ECDC). http://ecdc.europa.eu/en/ publications/Publications/1111_SUR_Annual_Epidemiological_Report_on_ Communicable_Diseases_in_Europe.pdf.

14. Bericht Legionellen und Legionellose. Federal Office of Public Health FOPH. [http://www.bag.admin.ch/themen/medizin/00682/00684/01084/ index.html?lang=de]

15. Swiss Climate. Federal Office of Metereology and Climatology Meteo Swiss, FDHA Switzerland. (accessed 20 Oct 2012). [http://www. meteosvizzera.admin.ch/web/en/climate/swiss_climate.html]

16. Lionello P, Malanotte-Rizzoli P, Boscolo RPA, Artale V: The Mediterranean Climate: An Overview of the Main Characteristics and Issue. Dev Earth Env Sci 2006, 4:1-26.

17. Spinedi F: Influsso della circolazione atmosferica sul tempo e sul clima in Ticino. FDHA Switzerland: Federal Office of Metereology and Climatology Meteo Swiss; 2008. http://proclimweb.scnat.ch/Products/news-docs/ MV_clima-TI-confe.pdf.

18. Telesca L, Kanevski M, Tonini M, Pezzatti GB, Conedera M: Temporal patterns of fire sequences observed in Canton of Ticino (southern Switzerland). Nat Hazards Earth System Sci 2010, 10:723-728.

19. Hryhorczuk D, Curtis L, Scheff P, Chung J, Rizzo M, Lewis C, Keys N, Moomey M: Bioaerosol emissions from a suburban yard waste composting facility. Ann Agric Environ Med 2001, 8(2):177-185.

20. Conza L, Casati S, Gaia V: Detection limits of Legionella pneumophila in environmental samples after co-culture with Acanthamoeba polyphaga. BMC Microbiol 2013, 13(1):49.

21. Conza L, Casati S, Gaia V: Presence of Legionella and free-living amoebae in composts and bioaerosols from composting facilities. PLOS ONE 4 8(7):e68244. doi:10.1371/journal.pone.0068244.

22. Thomas V, Herrera-Rimann K, Blanc DS, Greub G: Biodiversity of amoebae and amoeba-resisting bacteria in a hospital water network. App/ Environ Microbiol 2006, 72(4):2428-2438.

23. Tesh MJ, Miller RD: Amino acid requirements for Legionella pneumophila growth. J Clin Microbiol 1981, 13(5):865-869.

24. Gaia V, Casati S, Tonolla M: Rapid identification of Legionella spp. by MALDI-TOF MS based protein mass fingerprinting. Syst Appl Microbiol 2011, 34(1):40-44.

25. Helbig JH, Bernander S, Castellani Pastoris M, Etienne J, Gaia V, Lauwers S, Lindsay D, Luck PC, Marques T, Mentula S, Peeters MF, Pelaz C, Struelens M, Uldum SA, Wewalka G, Harrison TG: Pan-European study on culture-proven Legionnaires' disease: distribution of Legionella pneumophila serogroups and monoclonal subgroups. Eur J Clin Microbiol Infect Dis 2002, 21(10):710-716.

26. Soverow JE, Wellenius GA, Fisman DN, Mittleman MA: Infectious disease in a warming world: how weather influenced West Nile virus in the United States (2001-2005). Environ Health Perspect 2009, 117(7):1049-1052.

27. Karagiannis I, Brandsema P, M VDS: Warm, wet weather associated with increased Legionnaires' disease incidence in The Netherlands. Epidemio Infect 2009, 137(2):181-187

28. Fisman DN, Lim S, Wellenius GA, Johnson C, Britz P, Gaskins M, Maher J, Mittleman MA, Spain CV, Haas CN, Newbern C: It's not the heat, it's the humidity: wet weather increases legionellosis risk in the greater Philadelphia metropolitan area. J Infect Dis 2005, 192(12):2066-2073.

29. Hambleton P, Broster MG, Dennis PJ, Henstridge R, Fitzgeorge R, Conlan JW: Survival of virulent Legionella pneumophila in aerosols. J Hyg (Lond) 1983, 90(3):451-460.

30. Conza L, Casati S, Limoni C, Gaia V: Meteorological factors and risk of community-acquired Legionnaires' disease in Switzerland: an epidemiological study. BMJ Open 2013, 3(3):e002428. doi:10.1136/ bmjopen-2012-002428.

31. Rodriguez-Zaragoza S: Ecology of free-living amoebae. Crit Rev Microbiol 1994, 20(3):225-241.

32. Ahmed W, Huygens F, Goonetilleke A, Gardner T: Real-time PCR detection of pathogenic microorganisms in roof-harvested rainwater in Southeast Queensland, Australia. Appl Environ Microbiol 2008, 74(17):5490-5496.

33. Ahmed W, Vieritz A, Goonetilleke A, Gardner T: Health risk from the use of roof-harvested rainwater in Southeast Queensland, Australia, as potable or nonpotable water, determined using quantitative microbial risk assessment. Appl Environ Microbiol 2010, 76(22):7382-7391.

34. Sakamoto R, Ohno A, Nakahara T, Satomura K, Iwanaga S, Kouyama Y, Kura F, Kato N, Matsubayashi K, Okumiya K, Yamaguchi K: Legionella pneumophila in rainwater on roads. Emerg Infect Dis 2009, 15(8):1295-1297. 
35. Schalk JA, van Leeuwen Docters AE, Lodder WJ, de Man H, Euser S, den Boer JW, de Roda Husman AM: Isolation of Legionella pneumophila from pluvial floods by amoebal coculture. Appl Environ Microbiol 2012, 78(12):4519-4521.

36. Domingo JL, Nadal M: Domestic waste composting facilities: a review of human health risks. Environ Int 2009, 35(2):382-389.

37. den Boer JW, Yzerman EP, Jansen R, Bruin JP, Verhoef LP, Neve G, van der Zwaluw K: Legionnaires' disease and gardening. Clin Microbiol Infect 2007, 13(1):88-91.

doi:10.1186/1756-0500-7-831

Cite this article as: Conza et al:: Influence of climate and geography on the occurrence of Legionella and amoebae in composting facilities. BMC Research Notes 2014 7:831.

\section{Submit your next manuscript to BioMed Central and take full advantage of:}

- Convenient online submission

- Thorough peer review

- No space constraints or color figure charges

- Immediate publication on acceptance

- Inclusion in PubMed, CAS, Scopus and Google Scholar

- Research which is freely available for redistribution 